\title{
An Observational Study of Midline Abdominal Wound Closure Using Small Tissue Bites versus Large Tissue Bites with Reference to Surgical Site Infections and Wound Dehiscence
}

\author{
Yaqoob Hassan', Nayeem Ul Hassan'1, Ishfaq Ahmad Gilkar1, Ifat Irshad², \\ Y. Bashir ${ }^{2}$, Aashiq Hussain ${ }^{1}$, Syed Mushtaq Ahmad Shah ${ }^{1}$ \\ ${ }^{1}$ GMC Srinagar, Srinagar, India \\ ${ }^{2}$ Government Medical College, Srinagar, India \\ Email: dryaqoobwani@gmail.com
}

How to cite this paper: Hassan, Y., Hassan, N.U., Gilkar, I.A., Irshad, I., Bashir, Y., Hussain, A. and Shah, S.M.A. (2018) An Observational Study of Midline Abdominal Wound Closure Using Small Tissue Bites versus Large Tissue Bites with Reference to Surgical Site Infections and Wound Dehiscence. Surgical Science, 9, 399-406. https://doi.org/10.4236/ss.2018.911046

Received: June 13, 2018

Accepted: November 20, 2018

Published: November 23, 2018

Copyright $\odot 2018$ by authors and Scientific Research Publishing Inc. This work is licensed under the Creative Commons Attribution-NonCommercial International License (CC BY-NC 4.0). http://creativecommons.org/licenses/by-nc/4.0/ (c) (i) (8) Open Access

\begin{abstract}
Background: Midline incisions have advantage of rapid and wide access to the abdominal cavity with minimal damage to muscles, nerves and the vascular supply of the abdominal wall, hence causing minimal long term morbidity. The techniques of wound closure after midline laparotomy differ among operating surgeons and institutions. Faulty techniques and suture materials used play a crucial role in post-operative wound complications like stich abscess, surgical site infections, wound burst and incisional hernia. Aims: The aim of this study is to assess the outcome of midline abdominal wound closure using small tissue bites versus large tissue bites with reference to surgical site infection and wound dehiscence. Materials and methods: The study is the prospective observational study conducted in the department of general surgery Government Medical College Srinagar. A total of 100 cases were enrolled and studied who underwent midline laparotomy in the elective as well as emergency settings from 2015 to 2018. In 50 patients midline incisions were closed with large tissue bites placed at least $10 \mathrm{~mm}$ from the wound edge and $10 \mathrm{~mm}$ apart and in another 50 patients small tissue bites were used placed $5-7 \mathrm{~mm}$ from the wound edge and $5-7 \mathrm{~mm}$ apart and included only the aponeurosis in the stitches without peritoneum. Results: In all, 100 patients, 50 patients were subjected to large tissue bites and another 50 patients to small tissue bites. 15 patients out of 50 patients (30\%) in large tissue bites group and 10 patients (20\%) in small tissue bites developed surgical site infection. 8 patients out of 50 patients (16\%) in large tissue bites group and 4 patients $(8 \%)$ in small tissue bites developed wound dehiscence. Conclusion:
\end{abstract}


A total of 100 patients who underwent abdominal surgery through midline incision were divided into two groups. In 50 patients midline wound was closed using large tissue bites and in other 50 patients; small tissue bites was used to close midline incision including only aponeurosis. The research findings show that the small stitch length between 5 to $7 \mathrm{~mm}$ depending on the wound site is the ideal stitch length to close a midline incision. However, there was no statistical deference seen in both groups with reference to surgical site infection and wound dehiscence.

\section{Keywords}

Surgical Site Infection, Wound Dehiscence

\section{Introduction}

Midline incision is the most common incision performed in emergency setting as it gives excellent exposure to all the quadrant of abdomen. Midline incisions have advantage of rapid and wide access to the abdominal cavity with minimal damage to muscles, nerves and the vascular supply of the abdominal wall. The incision can be made quickly taking seven minutes on an average [1] [2] [3] [4]. The complications after laparotomy include surgical site infection, stitch abscess, incisional hernia, wound dehiscence, and evisceration [5]; however, wound complications after any laparotomy increases burden on resources of the health care system [6].

Wound infection and wound dehiscence after laparotomy are likely to be followed by incisional hernia within months or perhaps a few years.

Dehiscence most often develops 7 to 10 days postoperatively but may occur any time after surgery from 1 to more than 20 days [7]. The factors responsible can be categorized into two groups: patient factors and surgical factors. The patient factors include age, body mass index, chronic illness, cancer, infection, anemia, scurvy, and increased intra-abdominal pressure. Usually, it is not possible to control these factors. The factors which can be controlled are surgical factors which include the type of incisions, suture material, and the method of closure. It is in this area that the surgeon must concentrate his efforts to minimize wound complications [8].

According to the Jenkins it is recommended that incisions should be closed with a suture length (SL) to wound length (WL) ratio (the ratio of the length of the suture used through the length of the wound) of at least 4 . When the SL to $\mathrm{WL}$ ratio is less than 4 , the risk of wound site complications is 3 times higher [9] [10] [11]. The ratio depends on the size of each stitch and the stitch interval. Thus, a ratio of at least 4 can be achieved with many small stitches placed at close intervals or by incorporating a larger amount of tissue into stitches placed at greater intervals [12]. 


\section{Materials and Methods}

\subsection{Study Design}

Prospective observational study.

\subsection{Study Area}

The study was conducted in the department of General Surgery Government Medical College Srinagar.

\subsection{Study Population}

Patients admitted in general surgical and allied specialities who underwent midline laparotomy in elective as well as emergency settings.

\subsection{Study Sample}

Our study consisted of 100 consecutive patients undergoing abdominal surgery through a midline incision.

\subsection{Study Duration}

The study was conducted from 2015 to 2018 .

\subsection{Inclusion Criteria}

All patients $\geq 18$ years of age who undergoing abdominal surgery through midline incision in the emergency as well as in elective settings.

\subsection{Exclusion Criteria}

1) Patients with a previous midline incision.

2) Patients with hypoprotenemia, anaemia, diabetes or COPD.

\section{Methodology}

Patients were randomised in two groups A and B.

In group A (50 patients) midline incisions were closed with large tissue bites placed at least $10 \mathrm{~mm}$ from the wound edge and $10 \mathrm{~mm}$ apart and in group B (50 patients) small tissue bites were used placed $5-7 \mathrm{~mm}$ from the wound edge and $5-7 \mathrm{~mm}$ apart and included only the aponeurosis in the stitches without peritoneum.Polypropylene suture No.1 on round body needle was used in both the groups to close the abdomen. We performed continuous sutures in all our patients.

\section{Results}

The present prospective study was conducted in the Department of Surgery, Government Medical College Srinagar in a time period of three years.

The study population consisted of 100 consecutive patients undergoing abdominal surgery through a midline incision, fulfilling the inclusion criteria. 
The following observations were made.

\subsection{Demographic Charateristics}

In our study of 100 patients, mean age in the large tissue bites group was 47.43 years with standard deviation of 18.49 and the mean age in the small tissue bites group was 48.09 years with standard deviation of 18.26. Mean age between the two groups was comparable. No significant statistical differences were found in the age distribution between the two groups ( $\mathrm{p}$ value 1.0) as shown in Table 1.

\subsection{Serum Albumin}

Mean albumin levels of the large tissue bites group was 3.2 with standard deviation of 0.95 and that of the small tissue bites group was 3.30 with standard deviation of 0.77 .

There was no statistical difference in albumin levels between patients with or without complications as shown in Table 2.

\subsection{Ratio of Suture Length to Wound Length}

Mean suture length to wound length ratio in large tissue bites group was 4.84 and in small tissue bites group was 5.18. Ratio of suture to wound length was found to be statistically significant in the study groups with $p$ value of 0.001 as depicted in Table 3.

\subsection{Surgical Site Infections}

15 patients out of 50 patients in large tissue bites group and 10 patients out of 50 in small tissue bites developed surgical site infection. The difference was found to be statistically insignificant with $\mathrm{p}$ value of 0.355 as depicted in Table 4 .

Table 1. Demographic characteristics of study participants.

\begin{tabular}{ccc}
\hline Age (in years) & Large tissue bites & Small tissue bites \\
\hline $19-29$ & 29 & 26 \\
$30-39$ & 6 & 11 \\
$40-49$ & 7 & 4 \\
$50-59$ & 7 & 8 \\
$>60$ & 1 & 1 \\
Total & 50 & 50 \\
\hline
\end{tabular}

Table 2. Serum albumin values in the study population.

\begin{tabular}{cccc}
\hline Serum albumin & Large tissue bites & Small tissue bites & p value \\
\hline$<3$ & 21 & 17 & 0.536 \\
$\geq 3$ & 29 & 33 & \\
Total & 50 & 50 & 0.536 \\
\hline
\end{tabular}


Table 3. Suture length and wound length ratio in study groups.

\begin{tabular}{cccc}
\hline SL:WL Ratio & Large tissue bites & Small tissue bites & p value \\
\hline $4: 1-<5: 1$ & 38 & 21 & \\
$5: 1-6: 1$ & 12 & 29 & \\
Total & 50 & 50 & 0.001 \\
& S.D $=18.3$ & S.D $=5.6$ & \\
\hline
\end{tabular}

Table 4. Surgical site infection in study groups.

\begin{tabular}{cccc}
\hline SSI & Large tissue bites & Small tissue bites & p value \\
\hline Present & 15 & 10 & \\
Absent & 35 & 40 & 0.355 \\
Total & 50 & 50 & \\
& Mean $=25$ & Mean $=25$ & \\
& S.D $=14.14$ & S.D $=21.2$ & \\
\hline
\end{tabular}

\subsection{Wound Dehiscence}

8 patients out of 50 patients in large tissue bites group and 4 patients in small tissue bites developed wound dehiscence. The difference was found to be statistically insignificant with $\mathrm{p}$ value of 0.357 as depicted in Table 5 .

\section{Discussion}

The ideal suture method should aim at preventing post-operative wound site complication. Earlier surgeons chose the abdomen closure technique based on teaching, recommendation or personal experience. Dudley suggested the benefit from large tissue bites and thick sutures for safe abdominal closure [13]. Jenkins was probably the first to recommend a specific suture length (SL):wound length (WL) ratio on the basis of clinical studies and mathematical calculations. Jenkins gave a mathematical analysis to support this ratio derived from consideration of layered wound closure [11]. The aim of our study was to compare the outcome of midline abdominal wound closure after using small tissue bites versus large tissue bites with reference to surgical site infection and wound dehiscence.

\subsection{Age Distribution}

Mean age in the large tissue bites group was 47.43 years and the mean age in the small tissue bites group was 48.09 years (Table 1 ). Mean age between the two groups was comparable. No significant statistical differences were found in the age distribution between the two groups ( $p$ value of 1 ).

In a similar study done by Milbourn et al. [12] from 2001 to 2006, the difference between the mean age of their long stitch length group (64 years) and short stitch length group (65 years) was statistically insignificant (p value 0.30 ). In our study, the mean age was less than the study done by Milbourn et al. due to more 
Table 5. Wound dehiscence in study groups.

\begin{tabular}{cccc}
\hline Wound dehiscence & Large tissue bites & Small tissue bites & p value \\
\hline Present & 8 & 4 & \\
Absent & 42 & 46 & \\
Total & 50 & 50 & 0.357 \\
& S.D $=24.0$ & S.D $=29.6$ & \\
\hline
\end{tabular}

number of peptic and duodenal perforation cases in young age group secondary to Helicobactor pylori infestation and may be due to smoking, over the counter NSAID use and stress in our setting.

\subsection{Serum Albumin}

Mean albumin level of the large tissue bites group was 3.2 and that of the small tissue bites group was 3.3 (Table 2). Mean albumin levels between the two groups were comparable. No significant statistical differences were found in the serum albumin between the two groups ( $\mathrm{p}$ value 0.536 ). Out of the 15 surgical site infections in large tissue bites group, 12 patients had albumin level less than 3 and all the 10 patients in small tissue bites group who develop SSI, had albumin of less than 3. Higher number of patients with low albumin was due to baseline low levels of albumin in Indian setting.

In study done by Khan et al., [14] 28\% of patients with wound dehiscence had albumin less than $3.5 \mathrm{~g} / \mathrm{dl}$.

\subsection{Ratio of Suture Length to Wound Length}

Mean suture length to wound length ratio in large tissue bites group was 4.84 and in small tissue bites group was 5.18 (Table 3). Ratio of suture to wound length was found to be statistically significant in the study groups with $p$ value of 0.001 . In no case was a suture length to wound length ratio less than 4 . No case required a suture length more than 6 times the wound length.

In study done by Milbourn et al., [12] in long stitch length group, mean suture length to wound length ratio was 6.4 whereas in short stitch length group, suture length to wound length ratio was 5.7. This difference was significant statistically ( $\mathrm{p}$ value 0.001 ).

\subsection{Surgical Site Infection (SSI)}

15 patients out of 50 patients (30\%) in large tissue bites group and 10 patients $(20 \%)$ out of 50 patients in small tissue bites developed surgical site infection (Table 4). The difference was found to be statistically insignificant with $\mathrm{p}$ value of 0.355 . Most of the patients who developed surgical site infections in our study had undergone emergency surgery secondary to generalized peritonitis.

In study done by Milbourn et al., [12] 10.2\% patients in long stitch length group and 5.2\% patients in short stitch length group had surgical site infection. 


\subsection{Wound Dehiscence (WD)}

8 patients out of 50 patients (16\%) in large tissue bites group and 4 patients (8\%) in small tissue bites developed wound dehiscence (Table 5). The difference was found to be statistically insignificant with $\mathrm{p}$ value of 0.452 .

In study done by Milbourn et al., [12] 0.3\% patients in long stitch length group and none of the patients in short stitch length group had wound dehiscence. This difference was statistically insignificant with $\mathrm{p}$ value of more than 0.99 .

\section{Conflicts of Interest}

The authors declare no conflicts of interest regarding the publication of this paper.

\section{References}

[1] Guillou, P.J., Hall, T.J., Donaldson, D.R., Broughton, A.C. and Brennan, T.G. (1980) Vertical Abdominal Incisions-A Choice? British Journal of Surgery, 67, 395-399. https://doi.org/10.1002/bjs.1800670605

[2] Lip, H. (1981) De dwarse en vertikale incisie van de bovenbuik bij galblaasoperaties. Thesis, Erasmus University Rotterdam, Rotterdam.

[3] Kendall, S.W., Brennan, T.G. and Guillou, P.J. (1991) Suture Length to Wound Length Ratio and the Integrity of Midline and Lateral Paramedian Incisions. British Journal of Surgery, 78, 705-707. https://doi.org/10.1002/bjs.1800780623

[4] Lacy, P.D., Burke, P.E., O’Regan, M., Cross, S., Sheehan, S.J., Hehir, D., Colgan, M.P., Moore, D.J. and Shanik, G.D. (1994) The Comparison of Type of Incision for Transperitoneal Abdominal Aortic Surgery Based on Postoperative Respiratory Complications and Morbidity. European Journal of Vascular Surgery, 8, 52-55. https://doi.org/10.1016/S0950-821X(05)80120-3

[5] Burt, B.M., Tavakkolizadeh, A. and Ferzoco, S.J. (2007) Incisions, Closures, and Management of Abdominal Wound. In: Zinner, M.J. and Ashley, S.W., Eds., Maingot's Abdominal Operations, McGraw-Hill, New York, 71-101.

[6] Israelsson, L.A. and Wimo, A. (2000) Cost Minimisation Analysis of Change in Closure Technique of Midline Incisions. European Journal of Surgery, 166, 642-646. https://doi.org/10.1080/110241500750008312

[7] Kulaylat, M.N. and Dayton, M.T. (2012) Surgical Complications. In: Townsend, M., Beauchamp, R.D., Evers, B.M. and Mattox, K.L., Eds., Sabiston Textbook of Surgery: The Biological Basis of Modern Surgical Practice, Saunders Elsevier, Philadelphia, 281-327. https://doi.org/10.1016/B978-1-4377-1560-6.00013-5

[8] Sanders, R.J., DiClementi, D. and Ireland, K. (1977) Principles of Abdominal Wound Closure. Archives of Surgery, 112, 1184-1187. https://doi.org/10.1001/archsurg.1977.01370100038007

[9] Jenkins, T.P.N. (1976) The Burst Abdominal Wound: A Mechanical Approach. British Journal of Surgery, 63, 873-876. https://doi.org/10.1002/bjs.1800631110

[10] Israelsson, L.A. and Jinsson, T. (1993) Suture Length to Wound Length Ratio and Healing of Midline Laparotomy Incisions. British Journal of Surgery, 80, 1284-1286. https://doi.org/10.1002/bjs.1800801020

[11] Israelsson, L.A., Jonsson, T. and Knutson, A. (1996) Suture Technique and Wound 
Healing in Midline Laparotomy Incisions. European Journal of Surgery, 162, 605-609.

[12] Milbourn, D., Cengiz, Y. and Israelsson, L.A. (2009) Effect of Stitch Length on Wound Complications after Closure of Midline Incisions. The Archives of Surgery, 144, 1056-1059. https://doi.org/10.1001/archsurg.2009.189

[13] Dudley, H.A.F. (1970) Layered and Mass Closure of Abdominal Wall. A Theoretical and Experimental Analysis. British Journal of Surgery, 57, 664-667. https://doi.org/10.1002/bjs.1800570908

[14] Khan, M.N., Naqvi, A.H., Irshad, K. and Chaudhary, A.R. (2004) Frequency and Risk Factors of Abdominal Wound Dehiscence. Journal of College of Physicians and Surgeons Pakistan, 14, 355-357. 